\title{
Spatial-temporal variability of the fluctuation of water level in Poyang Lake basin, China
}

https://doi.org/10.1515/geo-2018-0075

Received June 18, 2018; accepted September 27, 2018

Abstract: Poyang Lake basin is one of the most biodiversity areas in China. Fluctuation of water level is an important factor of hydrological process which is a guarantee of ecosystem health and biodiversity conservation. To measure its spatial-temporal variation, classical statistical methods and permutation entropy were employed: 1) Variation of water level downstream of Poyang Lake during one year follows a periodical pattern, while it is random in upper reaches. That is, the range of water level in upper reaches is much less than that in downstream. 2) Fluctuation of water level in winter and spring is more complicated, more irregular and more random than that in other seasons. This is because in winter and spring, precipitation directly causes rising in water level rather than generating surface runoff, while it is reversed in summer. 3) The ranges, standard deviation, coefficient of variation and fluctuation of water level decrease with rising in elevation. 4) In sub-basin scale, fluctuation of water level in upper reaches is more complicated than that in downstream, especially along one river. Mechanically, catchment size and confluence process may be the main factors influencing fluctuation of water level over Poyang Lake basin.

Keywords: water level; spatial-temporal fluctuation; classical statistical methods; permutation entropy; Poyang Lake basin

\footnotetext{
*Corresponding Author: Changxiu Cheng: State Key Laboratory of Earth Surface Processes and Resource Ecology, Beijing Normal University, Beijing 100875, China

Key Laboratory of Environmental Change and Natural Disaster, Beijing Normal University, Beijing 100875, China Center for Geodata and Analysis, Faculty of Geographical Science, Beijing Normal University, Beijing 100875, China, E-mail: chengcx@bnu.edu.cn

Lixin Ning, Jing Yang, Changqing Song, Shi Shen: State Key Laboratory of Earth Surface Processes and Resource Ecology, Beijing Normal University, Beijing 100875, China

Key Laboratory of Environmental Change and Natural Disaster, Beijing Normal University, Beijing 100875, China Center for Geodata and Analysis, Faculty of Geographical Science, Beijing Normal University, Beijing 100875, China
}

\section{Introduction}

Basins, the basic unit of the earth's surface, are relatively independent and integrated natural geographic part that are composed of the water system and the land resources in a special region [1, 2]. As a critical zone of intense interaction between various circle layers of the earth [3-5], there exist numerous of energy flow and material circulation in basins, especially the downstream of low elevation, due to the intense interaction within internal elements [6]. Meanwhile, basins provide many necessary resources for human living and production; especially, the downstream area of low elevation is of great significance for human living as the main accumulation area of human $[7,8]$. In addition, it plays an irreplaceable role in the protection of biodiversity [9], climatic regulation [10], flood storage and drought relief [11], water conservation and purification [12], and maintenance of ecological balance [13]. Basins are known as "the kidney of the earth" for its special values $[14,15]$. Besides its function for providing material and protecting ecosystem, basins also have great value in other aspects, such as leisure, spirit and culture. However, with the growth of population and the development of the economy, in the next 40 years, more than $100 \%$ of fresh water and $50 \%$ of healthy food are needed to meet increasing human needs [16, 17]. Unfortunately, basins, as the main provider of fresh water and healthy food, are facing unprecedented challenges. Therefore, it is urgent for us to comprehensively understand the characteristics of basin, especially the downstream of low elevation, to effectively protect and utilize the resources and functions.

Water level is a hydrological variable and its fluctuations will affect a series of chemical, physical, and biological processes in basins $[18,19]$. And they play an important role in shaping the landscape and have a direct impact on the structure and function of basins for the reason that water is the most important medium of material transfer and the fundamental factor to maintain

Yunkai Zhou: College of Environment and Planning, Henan University, Kaifeng 475003, China 
the existence and occurrence of basins [20, 21]. During the past decades, a number of studies on the spatial pattern [22], temporal variation [23, 24], process [25] and forecasting [26] of water level have been carried out. It should be noted that the spatial-temporal variation of water level fluctuation at a basin scale has not been given enough attention, and the evidence of this is demonstrated in the number of relative research papers. Furthermore, those abovementioned studies on fluctuation of water level were mostly conducted by traditional statistical methods. Nevertheless, the time series of water level is non-stationary owning to the fact that the atmospheric system is a complex, nonlinear dynamic system [27]. Consequently, there are some shortcomings of analyzing water level time series by traditional statistical methods.

With the development of science and the improvement of the human cognitive level, complexity science, as a new inter-discipline, has been gradually recognized. Recently, a wave of researches related to complexity science are arising worldwide $[28,29]$. Under this condition, many complexity methods are emerging, which can be used to describe the laws that are impossible for the traditional statistical methods [30, 31]. For instance, the Hurst exponent is used to analyze the long-range correlation of events [32, 33]; the Power Spectrum is calculated to describe periodic characteristics of events [34]; and Information Theory is used to quantify the uncertainty of events [35]. Permutation entropy $(\mathrm{PE})$ is a measure of the complexity of a dynamic system based on the comparison of neighboring values [36]. It is a method used to describe the randomness or unpredictability of time series [37], which is widely used to analyze the economy [38], instrument stability [39], and physical fitness diagnosis [40, 41]. Additionally, the method is also used to analyze geographical phenomena successfully [42].

Poyang lake basin is one of the most important grain production bases and fisheries bases in China [9, 43]. Water level is needed to guarantee water availability for agricultural production and biological protection purposes. And its fluctuation is an important factor in the ecological and hydrological process. In the current study, traditional statistical methods and the complexity method, named permutation entropy, are employed to analyze the spatial and temporal variation of fluctuation of water level over the Poyang Lake basin. In addition, the correlation between fluctuation and elevation is discussed in detail. The specific objective of the research is to help people understanding how water level fluctuation vary with the elevation at a basin scale, which is a part of hydrological process. The main objective of the research is to provide a reference to correctly plant grain and vegetables according to local conditions, as well as effectively formulate ecological planning to protect biodiversity.

\section{Materials and Methods}

\subsection{Study Area}

Poyang Lake basin, located in the middle reaches of the Yangtze River (Figure 1), has a total area of $162200 \mathrm{~km}^{2}$, which accounts for nearly 9\% of the whole area of Yangtze River basin and $97 \%$ of the whole area of Jiangxi Province. The area is approximately located in middle reaches of Yangtze River between $27^{\circ} 3^{\prime} 18^{\prime \prime} \mathrm{N}$ and $29^{\circ} 55^{\prime} 35^{\prime \prime} \mathrm{N}$ latitude and between $114^{\circ} 41^{\prime} 35^{\prime \prime} \mathrm{E}$ and $11^{\circ} 50^{\prime} 26^{\prime \prime} \mathrm{E}$ longitude. The basin is one of the most important grain production bases and fisheries bases in China [9, 43]. Such a unique advantage of the basin is owing to the complete basin system combining mountains, lands, rivers and lakes [44]. Additionally, there exists a large number of plants and animals, and the biodiversity in Poyang Lake basin is extremely rich because of the abundant water and heat resources [45]. The area is characterized by subtropical humid monsoon climate, with an annual average temperature of approximately $18^{\circ} \mathrm{C}$ and annual precipitation of approximately $1634 \mathrm{~mm}$ [46]. The spatial and temporal distribution of precipitation is uneven in this area, and heavy rainfall frequently occurs over the period from April to June, which notably affects water resource distribution and brings about the frequent occurrences of drought and flood. The basin is divided into two parts by Songmen Mountain. Poyang Lake is located in the northern part, which is the largest fresh lake in China. As shown in Figure 1, five major rivers, the Ganjiang River, Fujiang River, Xinjiang River, Raohe River and Xiuhe River, discharge into Poyang Lake. Affected by seasonal precipitation, the water area of the lake fluctuates greatly during the year. The area of the lake can reach up to $3000 \mathrm{~km}^{2}$ in the wet season while shrinking to less than $1000 \mathrm{~km}^{2}$ in the dry season [47]. The topography of Poyang Lake is complex and diverse, such as mountains, hills, alluvial plains. The mountains are mostly spread in western and eastern parts, and the maximum elevation is $2200 \mathrm{~m}$ above the sea level. On the ontrary, the low alluvial plains are mostly spread in its central area. It has aboudant sunlight with 1473.3 to $2077.5 \mathrm{~h}$ annually during the period of 1961-2000. In the past few decades, a series of eco-environment problems, such as environmental pollution and biodiversity decline, have gradually appeared along with the growth of popula- 
tion and development of economy. The zone is facing severe challenges of sustainable development[48].

\subsection{Data}

The data used in this study mainly include water level data and precipitation data. Water level data was recorded every day by the author at approximately 9 a.m. from the website of the Water Resources Department of Jiangxi Province (http://www.jxsl.gov.cn). The water level was automatically measured using pressure transducers or noncontact transducers, based on reference of elevation system of Wusong. In order to study the hydrological regime of the whole basin of Poyang Lake, the totally 24 observation stations over the entire Poyang Lake basin were selected and their locations are shown in Figure 1. Hukou and Xingzi stations are located at the channel which joins the Poyang Lake and Yangtze river. In addition, two stations, three stations, ten stations, three stations, and three stations are located at Xiushui river basin, Raohe river basin, Ganjinag river basin, Fuhe river basin, and Xinjiang River basin respectively. Precipitation data was acquired from the website of The China Meteorological Data Service Center (http://data.cma.cn/), and the daily precipitation is the total precipitation fallen in the 24 hours and recorded at 8 p.m.. The time period selected for this study was from March 1, 2015 to February 28, 2017, for 731 days, or 2 years, in total. Other datasets are also needed, such as the DEM acquired from the website of the Geospatial Data Cloud (http://www.gscloud.cn/) and the boundary of the Poyang Lake basin. The elevations of all observation stations were picked up from the DEM by the author.

\subsection{Method}

Permutation entropy (PE) is a natural complexity measure for time series [36], which is drawn from chaos theory and can tell how much a series deviates from a completely random one $[49,50]$. The advantages of PE are its robustness, simplicity and fast calculation. The calculation process is as follows:

For a scalar time series $\{x(i), i=1,2, \ldots\}$, let us first reconstruct a m-dimensional space:

$$
X_{i}=\{x(i), x(i+d), \ldots, x(i+(m-1) d)\} .
$$

where $\mathrm{m}$ is called the embedding dimension and $d$ the delay time. Here, $m=3$ and $d=1$.

Then, the $m$ number of real values $X_{i}=\{x(i), x(i+$ $d), \ldots, x(i+(m-1) d)\}$ can be arranged in an increasing order:

$$
x\left(i+\left(j_{1}-1\right) d\right) \leq x\left(i+\left(j_{2}-1\right) d\right) \leq \ldots \leq x\left(i+\left(j_{m}-1\right) d\right) .
$$

Where $j$ is a new series according to the processing before.

When an equality occurs, e.g., $x\left(i+\left(j_{i 1}-1\right) d\right)=x(i+$ $\left.\left(j_{i 2}-1\right) d\right)$ we order $x$ according to their corresponding $j$. If $j_{i 1}<j_{i 2}$, we write $x\left(i+\left(j_{i 1}-1\right) d\right) \leq x\left(i+\left(j_{i 2}-1\right) d\right)$.

Therefore, any vector $X_{i}$ is uniquely mapped onto $\left\{j_{1}\right.$, $\left.j_{2}, \ldots, j_{m}\right\}$, which is one of the $m$ ! permutations. When each permutation is considered as a symbol, then $\mathrm{Xi}$ is represented by a symbol sequence. The number of distinct symbols can be at most $m$ !.

Let $P_{1}, P_{2}, \ldots, P_{k}$, represent the probability distribution for the distinct symbols, where $k \leq m$ !. Then, PE is defined as:

$$
P E(m)=-\sum_{j=1}^{k} P_{j} \ln P_{j}
$$

The maximum of $P E(m)$ is $\ln (m !)$. And it is convenient to work with

$$
0 \leq P E=P E(m) / \ln (m !) \leq 1
$$

Thus, PE gives a measure of the departure of the time series under study from a completely random one. Here, $0<P E<$ 1 ,. If $P E=1$, the time series is completely randomness. The smaller the value of $\mathrm{PE}$, the more regular the time series is. More details and a simple example of PE can be found in the paper [51].

\section{Results}

\subsection{Classical Statistical Methods to Analyze Water Level}

\subsubsection{Temporal variation of water level}

For the temporal variation in water level, Xingzi Station and Xiashan Station were selected as two examples to describe the temporal variation of water level (Figure 2). This is because of their different locations and elevations, where one is one of the lowest elevation stations located in the channel connecting Poyang Lake with the Yangtze River, and the other is one of the highest elevation stations located in the upper reaches (Figure 1).

In general, the variation in water level at Xingzi Station and Xiashan Station in 2015 displays different patterns. A periodical pattern, approximately a single peak or 


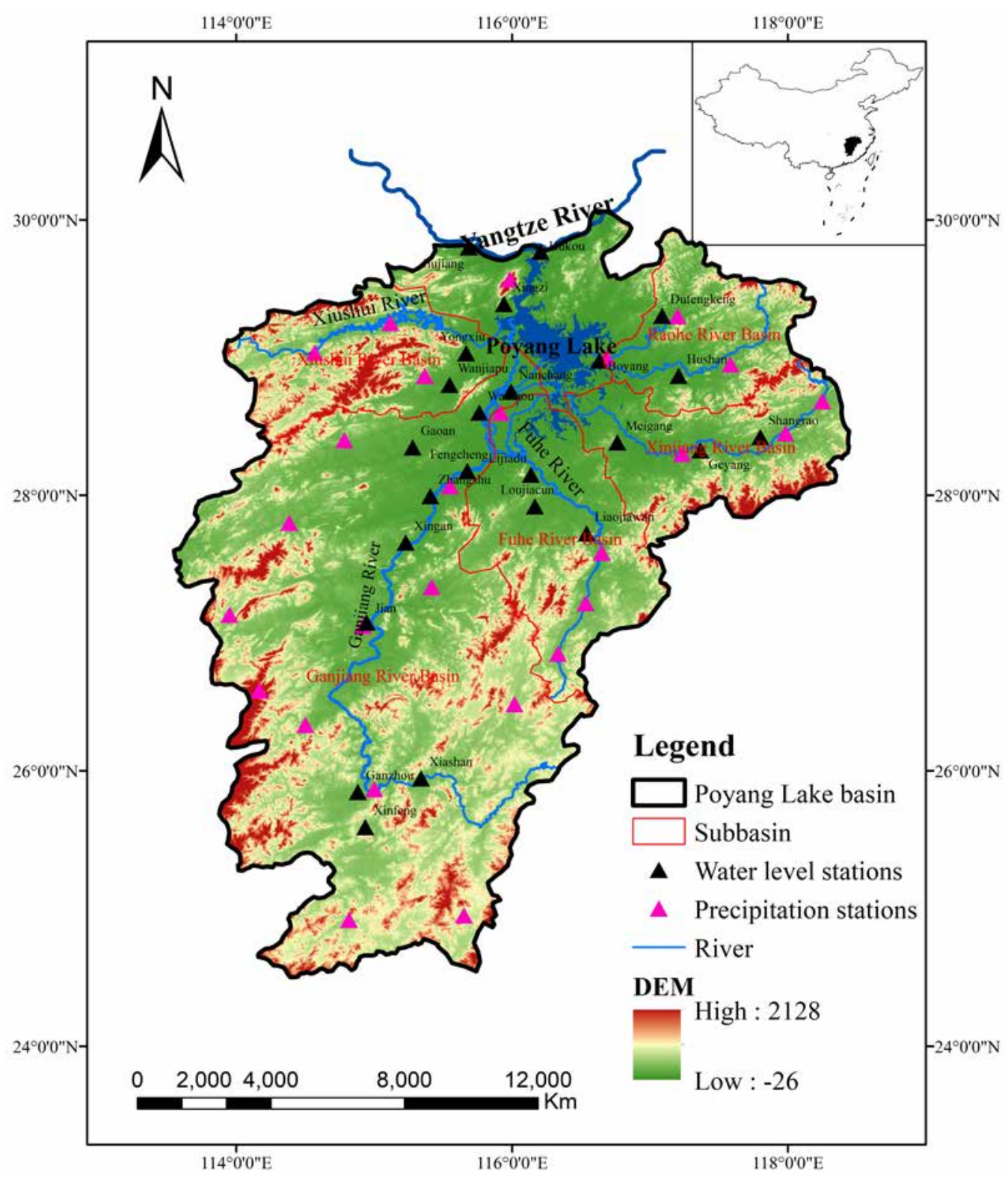

Figure 1: Location of the study area and observation stations

a sinusoid, can be easily found for the variation of water level at Xingzi Station. Precisely, the water level in June and July was highest, and then it decreased until February, which was lowest during the year. After February, the water level experienced a significant increase until June. The average water levels of these two periods are $18.00 \mathrm{~m}$ and $11.26 \mathrm{~m}$, respectively. In contrast, there is no obvious periodic pattern of water level fluctuation at Xiashan Station, except for one highest value which may be caused by extreme precipitation or measuring error. In other words, there is no obvious difference of water level between summer and winter. As seen in the figure, the range of the water level at Xiashan Station is especially narrow, and the value basically fluctuates around $109.5 \mathrm{~m}$.

\subsubsection{Spatial variation of water level}

The water level data of 24 observation stations in Poyang Lake basin were collected to calculate values, such as range, standard deviation and coefficient of variation, using traditional statistics methods. The results are presented in Table 1, which includes some of the descriptive statistical values for water level at different observation stations. 
Table 1: Traditional statistics of water level at 24 observation stations in 2015

\begin{tabular}{|c|c|c|c|c|c|c|c|c|c|c|c|c|}
\hline Stations & Hukou & Jiujiang & Nanchang & Boyang & Fengcheng & Xingzi & Yongxiu & Zhangshu & Gaoan & Waizhou & Loujiawun & Geyang \\
\hline Range & 9.85 & 9.64 & 7.84 & 5.98 & 9.6 & 9.65 & 6.19 & 9.36 & 4.88 & 8.12 & 3.85 & 7.58 \\
\hline \multicolumn{13}{|l|}{ Standard } \\
\hline Deviation & 2.527 & 2.485 & 1.689 & 1.487 & 1.98 & 2.429 & 1.477 & 2.038 & 0.73 & 1.734 & 0.598 & 0.954 \\
\hline \multicolumn{13}{|l|}{ Coefficient } \\
\hline of Variation & 0.191 & 0.181 & 0.102 & 0.097 & 0.109 & 0.18 & 0.09 & 0.089 & 0.031 & 0.104 & 0.018 & 0.025 \\
\hline Elevation & 1 & 5 & 12 & 19 & 22 & 27 & 28 & 30 & 38 & 43 & 43 & 44 \\
\hline Stations & Xingan & Jian & Hushan & Wanjiapu & Meigang & Dufengkeng & Lijiadu & Shangrao & Ganzhou & Liaojiawan & Xiashan & Xinfeng \\
\hline Range & 7.36 & 8.06 & 7.1 & 7.1 & 9.36 & 3.9 & 6.19 & 2.57 & 8.13 & 3.86 & 2.34 & 3.47 \\
\hline \multicolumn{13}{|l|}{ Standard } \\
\hline Deviation & 1.421 & 1.212 & 1.117 & 0.831 & 1.488 & 0.494 & 1.08 & 0.542 & 1.132 & 0.363 & 0.204 & 0.513 \\
\hline \multicolumn{13}{|l|}{ Coefficient } \\
\hline of Variation & 0.046 & 0.027 & 0.054 & 0.04 & 0.08 & 0.021 & 0.045 & 0.008 & 0.012 & 0.01 & 0.002 & 0.004 \\
\hline Elevation & 47 & 47 & 55 & 60 & 65 & 87 & 92 & 98 & 100 & 117 & 127 & 150 \\
\hline
\end{tabular}

In general, the maximum range of water level in 2015 appears at Hukou Station which is $9.850 \mathrm{~m}$, while the minimum appears at Xiashan Station which is $2.34 \mathrm{~m}$. The maximum standard deviation of water level appears at Hukou Station, while the minimum appears at Xiashan Station, and it ranges from 0.204 to $2.527 \mathrm{~m}$. The maximum coefficient of variation of water level appears at Hukou Station, while the minimum is at Xiashan Station, and it ranges from 0.002 to $0.191 \mathrm{~m}$. In addition, it is easy to find that Jiujiang and Hukou are stations of lowest elevation, while Xiashan is the station of highest elevation.

To understand the relationship between elevation and the descriptive statistical values, the Pearson correlation coefficient was calculated. As seen in Table 2, there are significant correlations between elevation and range, standard deviation, coefficient of variation of water level at the 24 stations. Range, as well as standard deviation and coefficient of variation, will decrease with the increase in elevation, and the Pearson correlation coefficients are $-0.694,-0.782$, and -0.761 , respectively.

\subsection{PE to Analyze Fluctuation of Water Level}

\subsubsection{Temporal variation in fluctuation of water level}

For the temporal variation of fluctuation of water level, the PE method was applied to the seasonal water level data of different stations (Table 3). This paper selected periods from March to May, from June to August, from September to November, and from December to February as spring, summer, autumn and winter, respectively.

In general, there is a difference in fluctuation of water level over Poyang Lake basin, and the correlation between elevation and $P E$ varies with seasons. The average $P E$ value of water level at 24 stations in winter was 0.862 , which was the maximum, followed by spring, autumn, summer, whose average PE values were $0.848,0.840$ and 0.825 , respectively. This implies that the fluctuation of water level in winter and spring is more irregular and random than that in other seasons, while it is reversed in summer. An interesting appearance that can be observed is that the maximum PE value of water level appears at Xinfeng Station, whose elevation is $150 \mathrm{~m}$, the highest of all stations, while the minimum PE value appears at stations which almost have lowest elevation. 
Table 2: Correlation between elevation and classical statistical value of water level in 2015

\begin{tabular}{lcccc}
\hline $\begin{array}{c}\text { Pearson } \\
\text { Correlation Coefficient }\end{array}$ & Elevation & Range & Standard Deviation & Coefficient of Variation \\
\hline Elevation & 1 & $-0.694^{\star \star}$ & $-0.782^{\star \star}$ & $-0.761^{\star \star}$ \\
Range & - & 1 & $0.886^{\star \star}$ & $0.744^{\star \star}$ \\
Standard Deviation & - & - & 1 & $0.941^{\star \star}$ \\
Coefficient of Variation & - & - & - & 1 \\
\hline ** Correlation is significant at the 0.01 level (2-tailed)
\end{tabular}

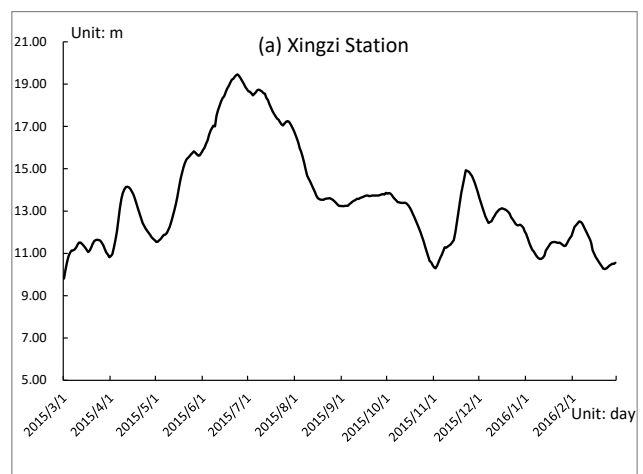

(a)

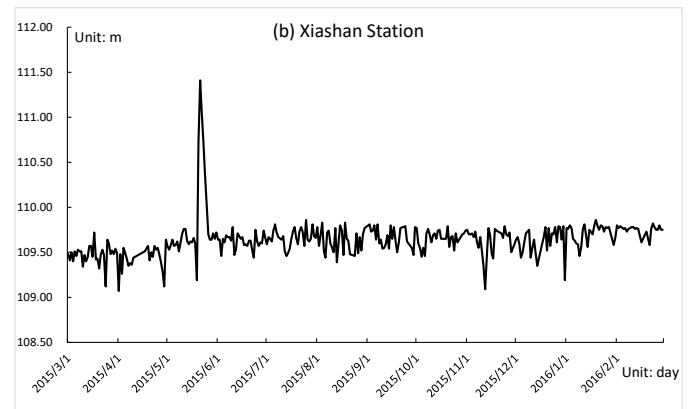

(b)

Figure 2: Temporal variations of the water level during period from March 1, 2015 to February 29, 2016: (a) temporal variation of water level at Xingzi Station; (b) temporal variation of water level at Xiashan Station.
Pearson correlation coefficient were calculated to analyze the correlation between PE value and elevation (Table 3). A separate analysis for each season indicated that there is a significantly positive correlation between the elevation and PE of water level, while it varies with seasons. The highest Pearson correlation coefficient occurs in summer, and the coefficient is 0.738 , followed by spring, winter, autumn, whose coefficients are $0.652,0.556$, and 0.548 , respectively.

\subsubsection{Spatial pattern in fluctuation of water level}

For the spatial pattern of fluctuation of water level, the PE method was applied to the water level data at 24 observation stations distributing over the whole study period (Table 4).

The results show that there are obvious different PE values at 24 stations distributing over the Poyang Lake basin. In general, all PE values of water level are higher than 0.6 , which varies with elevation. The maximum PE appears at Xinfeng Station, while the minimum appears at Jiujiang Station, and the range is between 0.628 and 0.989 .

Furthermore, correlation analysis was applied again, and Pearson correlation coefficients are listed. It shows that a significant positive correlation can be found between elevation and PE values, and the correlation coefficient is 0.655 . This suggests that the PE of water level increased obviously with the increase of elevation over the Poyang Lake basin. That is, the degree of water level fluctuation increased.

Of course, this is a general trend of fluctuation of water level over the basin. It should be noted that a more pronounced characteristic is that in the sub-basin scale, the fluctuation of the water level in the upper reaches is 
Table 3: PE values of water level in different seasons and their correlations with elevation in 2015

\begin{tabular}{|c|c|c|c|c|c|}
\hline Station & Elevation & Spring & Summer & Autumn & Winter \\
\hline Hukou & 1 & 0.573 & 0.580 & 0.741 & 0.595 \\
\hline Jiujiang & 5 & 0.573 & 0.603 & 0.688 & 0.585 \\
\hline Nanchang & 12 & 0.783 & 0.767 & 0.668 & 0.821 \\
\hline Boyang & 19 & 0.782 & 0.680 & 0.745 & 0.745 \\
\hline Fengcheng & 22 & 0.853 & 0.768 & 0.823 & 0.881 \\
\hline Xingzi & 27 & 0.556 & 0.589 & 0.710 & 0.663 \\
\hline Yongxiu & 28 & 0.949 & 0.795 & 0.840 & 0.982 \\
\hline Zhangshu & 30 & 0.901 & 0.844 & 0.907 & 0.910 \\
\hline Gaoan & 38 & 0.848 & 0.877 & 0.906 & 0.877 \\
\hline Waizhou & 43 & 0.783 & 0.758 & 0.686 & 0.834 \\
\hline Loujiacun & 43 & 0.915 & 0.902 & 0.909 & 0.885 \\
\hline Geyang & 44 & 0.935 & 0.853 & 0.875 & 0.922 \\
\hline Xingan & 47 & 0.881 & 0.889 & 0.868 & 0.951 \\
\hline Jian & 47 & 0.917 & 0.912 & 0.954 & 0.938 \\
\hline Hushan & 55 & 0.852 & 0.826 & 0.851 & 0.859 \\
\hline Wanjiapu & 60 & 0.873 & 0.892 & 0.944 & 0.965 \\
\hline Meigang & 65 & 0.780 & 0.695 & 0.810 & 0.866 \\
\hline Dufengkeng & 87 & 0.922 & 0.985 & 0.929 & 0.955 \\
\hline Lijiadu & 92 & 0.922 & 0.877 & 0.845 & 0.881 \\
\hline Shangrao & 98 & 0.947 & 0.969 & 0.970 & 0.916 \\
\hline Ganzhou & 100 & 0.920 & 0.848 & 0.765 & 0.836 \\
\hline Liaojiawan & 117 & 0.972 & 0.970 & 0.870 & 0.944 \\
\hline Xiashan & 127 & 0.919 & 0.946 & 0.887 & 0.898 \\
\hline Xinfeng & 150 & 0.992 & 0.979 & 0.966 & 0.983 \\
\hline & & 0.848 & 0.825 & 0.840 & 0.862 \\
\hline \multicolumn{2}{|c|}{ Pearson Correlation Coefficient } & $0.652^{\star \star}$ & $0.738^{* *}$ & $0.548^{\star *}$ & 0.556 ** \\
\hline
\end{tabular}

** Correlation is significant at the 0.01 level (2-tailed) 
Table 4: PE values water level at 24 stations and their correlations with elevation in 2015

\begin{tabular}{|c|c|c|c|c|c|c|c|c|c|c|c|c|}
\hline \multirow{2}{*}{$\begin{array}{l}\text { Station } \\
\text { Elevation }\end{array}$} & \multirow{2}{*}{$\begin{array}{c}\text { Jiujiang } \\
5\end{array}$} & \multirow{2}{*}{$\begin{array}{c}\text { Hukou } \\
1\end{array}$} & \multirow{2}{*}{$\begin{array}{c}\text { Xingzi } \\
27\end{array}$} & \multirow{2}{*}{$\begin{array}{c}\text { Yongxiu } \\
28\end{array}$} & \multicolumn{2}{|c|}{ Wanjiapu Waizhou } & \multicolumn{3}{|c|}{ Nanchang Dufengkeng Boyang } & \multicolumn{3}{|c|}{ Hushan Meigang Geyang } \\
\hline & & & & & 60 & 43 & 12 & 87 & 19 & 55 & 65 & 44 \\
\hline PE value & 0.628 & 0.638 & 0.647 & 0.914 & 0.930 & 0.789 & 0.790 & 0.960 & 0.754 & 0.860 & 0.807 & 0.904 \\
\hline Station & Shangrao & Gaoan & Zhangshu & Fengcheng & Lijiadu & Loujiacun & Liaojiawan & Xingan & Jian & Ganzhou & Xiashan & Xinfeng \\
\hline Elevation & 98 & 38 & 30 & 22 & 92 & 43 & 117 & 47 & 47 & 100 & 127 & 150 \\
\hline PE value & 0.959 & 0.885 & 0.902 & 0.859 & 0.888 & 0.910 & 0.948 & 0.916 & 0.940 & 0.855 & 0.920 & 0.989 \\
\hline & & Pearso & Correlat & Coeffic & : & 0.65 & $(\mathrm{PE}=$ & $17 \times \mathrm{El}$ & $n+$ & $626)$ & & \\
\hline
\end{tabular}

** Correlation is significant at the 0.01 level (2-tailed)

more complicated than that in the downstream. To make it more obvious, the five main sub-basins were extracted, which are shown in Figure 3, as well as the river and stations. Take the Xinjiang River basin (Figure 3c) as an example, the PE value of water level at Meigang Station is 0.807 , which is located in the downstream of the subbasin. While at Geyang Station, located in the middle reaches, the PE value is 0.904 , which was lower than $\mathrm{PE}$ at Shangrao Station located in the upper reaches. A similar trend can be found in the Xiushui River basin, Raohe River basin, and Fuhe River basin. However, in the Ganjiang River basin, the variation of $\mathrm{PE}$ is more complicated. Jian Station and Waizhou are exceptions, whose PE values are higher than the stations located in the upper reaches.

\section{Discussion}

The spatial-temporal variability of fluctuation of water level in Poyang Lake in 2015 was analyzed, and some meaningful results were drawn. Furthermore, The Spatialtemporal variability of water level fluctuation in 2016 was also analyzed by the same methods, and similar results were drawn (Tables and Figures in supplementary materials).

Climate change, land use, sediment deposition, and geological hazards affect the fluctuation of water level to varying degrees [52, 53]. In general, spatial fluctuation in water level is mainly affected by spatial variation in precipitation [54]. Therefore, in order to analyze the spatial variation of precipitation and its correlation with the fluc- tuation of water level over Poyang Lake, some values, such as PE, average, range, standard deviation and coefficient of variation, were employed using daily precipitation data at 26 precipitation monitoring stations in 2015, which distributing over the Poyang Lake basin. Furthermore, the Pearson correlation coefficient was calculated to quantify the correction between elevation and the abovementioned values (Table 5).

As we can see in Figure 1, 26 precipitation stations are evenly distributed over the whole Poyang Lake basin. In addition, an important result is that there is no obvious spatial characteristics of $\mathrm{PE}$, average, range, standard deviation, coefficient of variation, or total precipitation over basin. Furthermore, the Pearson correlation coefficients are not high enough to say that they significantly correlated with elevation (Table 5). In other words, there is no significant correlation between elevation and characteristics of precipitation over the whole basin. Consequently, it is a correct conclusion that the fluctuation of water level increased with the increasing of elevation over the Poyang Lake basin.

For the temporal variation of water level fluctuation, it appears that the fluctuation of water level is more random in winter and spring than that in other seasons, while it is more regular in summer. Several researches have demonstrated that meteorological factor, e.g. precipitation and air temperature, may contributed to the temporal variation of water level in basin on a long timescale [55-57]. By analyzing the water level changes in Polish lakes, Wrzesiński [55] discovered that variable precipitation will directly result in fluctuation of water level, and high temperature will cause intensive evaporation of surface wa- 

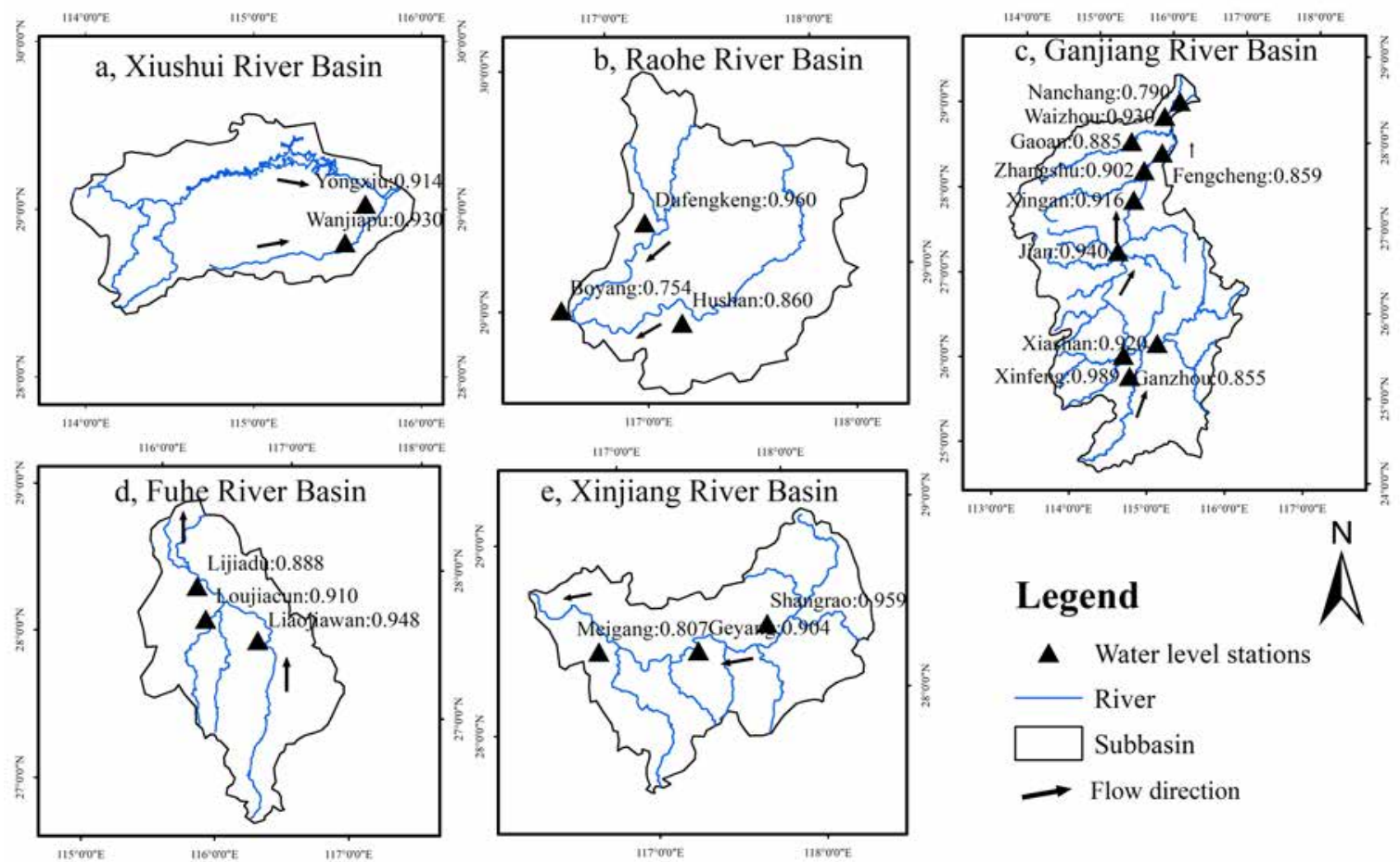

Figure 3: PE values of stations in the five sub-basins of the study area: (a) Xiushui River Basin, (b) Raohe River Basin, (c) Ganjiang River Basin, (d) Fuhe River Basin and (e) Xinjiang River Basin.

ter bodies which will affect water level. But, on a seasonal timescale, the effect of evaporation on water level is significantly smaller than precipitation [57, 58]. Mechanically, there is less precipitation in winter and spring. Additionally, due to human irrigation and utilization, water resources in this basin have been extensively used. Consequently, the water level is lower at different reservoirs and rivers, as well as observation stations, in winter and spring. Indeed, when precipitation occurs, it will directly replenish the local water resources, raising the water level instead of generating surface runoff. It may be occurring only when the rainfall is large enough. In contrast, there is enough precipitation in summer. The water level at hydrological stations and reservoirs has reached its saturation. Hence, precipitation will cause surface runoff once rainfall happens, which results in lower fluctuation of water level in summer.

For the spatial pattern of water level fluctuation, it appears that the water level in upper reaches tends to fluctuate around a certain value, while the variation of water level downstream tends to have a periodical peak pattern and its fluctuation is lower than that in the upper reaches. This tendency can be attributed to catchment size (Table 6), for the reason that the correlation between calculated values and catchment size of stations are more significant.
This suggested that the size of the catchment area is the main reason for the spatial variation of water level over the basin. In the upper reaches of Poyang Lake basin, there is no certain period of variation of water level due to the randomness of precipitation, slope and topography. In contrast, the variation of water level downstream reflects the variation of precipitation over the whole basin, and it is mainly influenced by the basin climate rather than precipitation at a certain point. The process of surface runoff was responsible for this phenomenon. Physically, precipitation may be random at a certain zone, while it is regular and periodic over the whole basin. All of the abovementioned reasons contribute to randomness and unpredictability of water level in the upper reaches of the Poyang Lake basin than that in downstream areas. Furthermore, the trend is more obvious at the sub-basin scale, especially along one river. That is, along one river, the fluctuation of water level at a higher elevation, whose PE is close to 1 , is more complicated than that at lower elevation. This could be confirmed by water level fluctuation in Xiushui River basin, Raohe River basin, Fuhe River basin, and Xinjiang River basin. However, in Ganjiang River basin, Jian and Waizhou Stations do not conform to this trend. Their spatial location caused this phenomenon. Take Jian Station as an example. The station is located in the Lujiang 
Table 5: Values of all precipitation stations and their correlations with elevation in 2015

\begin{tabular}{|c|c|c|c|c|c|c|c|c|c|}
\hline Station & Latitude & Longitude & Elevation & PE & Average & Range & $\begin{array}{l}\text { Standard } \\
\text { Deviation }\end{array}$ & $\begin{array}{l}\text { Coefficient } \\
\text { of Variation }\end{array}$ & $\begin{array}{c}\text { Total } \\
\text { precipitation }\end{array}$ \\
\hline 57598 & 29.033 & 114.567 & 146.800 & 0.855 & 5.140 & 96.300 & 12.641 & 2.459 & 1881.3 \\
\hline 57696 & 28.400 & 114.783 & 91.700 & 0.912 & 5.644 & 78.400 & 11.671 & 2.068 & 2065.6 \\
\hline 57789 & 27.133 & 113.950 & 194.500 & 0.892 & 5.490 & 157.400 & 13.611 & 2.479 & 2009.2 \\
\hline 57793 & 27.800 & 114.383 & 131.300 & 0.892 & 5.699 & 128.800 & 12.581 & 2.208 & 2085.8 \\
\hline 57799 & 27.050 & 114.917 & 71.200 & 0.877 & 6.045 & 88.400 & 12.993 & 2.149 & 2212.3 \\
\hline 57894 & 26.583 & 114.167 & 843.000 & 0.922 & 5.861 & 97.100 & 10.865 & 1.854 & 2145.2 \\
\hline 57896 & 26.333 & 114.500 & 126.100 & 0.873 & 5.243 & 96.500 & 11.348 & 2.164 & 1918.8 \\
\hline 57993 & 25.867 & 115.000 & 137.500 & 0.864 & 5.038 & 114.200 & 11.584 & 2.299 & 1843.9 \\
\hline 58506 & 29.567 & 115.983 & 1164.500 & 0.884 & 7.389 & 283.500 & 21.180 & 2.866 & 2704.3 \\
\hline 58507 & 29.250 & 115.117 & 116.000 & 0.814 & 5.033 & 164.400 & 14.558 & 2.893 & 1842.0 \\
\hline 58519 & 29.000 & 116.683 & 40.100 & 0.836 & 5.187 & 134.800 & 13.565 & 2.615 & 1898.5 \\
\hline 58527 & 29.300 & 117.200 & 61.500 & 0.860 & 6.381 & 88.100 & 14.277 & 2.237 & 2335.4 \\
\hline 58600 & 28.867 & 115.367 & 78.900 & 0.852 & 5.472 & 166.000 & 14.242 & 2.603 & 2002.9 \\
\hline 58606 & 28.600 & 115.917 & 46.900 & 0.876 & 5.951 & 119.700 & 15.048 & 2.529 & 2177.9 \\
\hline 58608 & 28.067 & 115.550 & 30.400 & 0.888 & 6.087 & 133.000 & 13.928 & 2.288 & 2228.0 \\
\hline 58622 & 28.950 & 117.583 & 88.500 & 0.882 & 7.549 & 244.300 & 19.254 & 2.551 & 2762.8 \\
\hline 58626 & 28.300 & 117.233 & 60.800 & 0.883 & 6.630 & 97.200 & 14.655 & 2.210 & 2426.7 \\
\hline 58634 & 28.683 & 118.250 & 116.300 & 0.903 & 7.043 & 169.200 & 16.947 & 2.406 & 2577.6 \\
\hline 58637 & 28.450 & 117.983 & 118.200 & 0.901 & 6.378 & 107.400 & 13.467 & 2.111 & 2334.4 \\
\hline 58705 & 27.333 & 115.417 & 85.700 & 0.883 & 6.580 & 133.900 & 15.831 & 2.406 & 2408.3 \\
\hline 58715 & 27.583 & 116.650 & 80.800 & 0.906 & 7.133 & 95.300 & 14.878 & 2.086 & 2610.8 \\
\hline 58718 & 27.217 & 116.533 & 111.500 & 0.902 & 7.131 & 139.600 & 15.785 & 2.214 & 2609.8 \\
\hline 58806 & 26.483 & 116.017 & 209.100 & 0.853 & 8.745 & 172.100 & 18.368 & 2.100 & 3200.7 \\
\hline 58813 & 26.850 & 116.333 & 143.800 & 0.871 & 7.771 & 92.200 & 15.867 & 2.042 & 2844.1 \\
\hline 59092 & 24.917 & 114.817 & 206.300 & 0.864 & 5.274 & 131.800 & 13.099 & 2.484 & 1930.2 \\
\hline 59102 & 24.950 & 115.650 & 303.900 & 0.871 & 5.585 & 102.400 & 12.529 & 2.243 & 2044.2 \\
\hline \multicolumn{4}{|c|}{ Pearson Correlation Coefficient } & 0.235 & 0.156 & $0.455^{\star}$ & 0.270 & 0.114 & 0.156 \\
\hline
\end{tabular}

** Correlation is significant at the 0.01 level (2-tailed) 
Table 6: Correlation all values with total precipitation at the year and seasonal timescale

\begin{tabular}{lccccc}
\hline Station & Catchment Size & Standard Deviation & Coefficient of variation & Range & PE \\
\hline Hukou & 162225 & 2.527 & 0.191 & 9.850 & 0.638 \\
Wanjiapu & 3548 & 0.831 & 0.040 & 7.100 & 0.930 \\
Waizhou & 80948 & 1.734 & 0.104 & 8.120 & 0.789 \\
Dufengkeng & 5013 & 0.494 & 0.021 & 3.900 & 0.960 \\
Hushan & 6374 & 1.117 & 0.054 & 7.100 & 0.860 \\
Meigang & 15535 & 1.488 & 0.080 & 9.360 & 0.807 \\
Lijiadu & 15811 & 1.080 & 0.045 & 6.190 & 0.888 \\
Loujiacun & 4969 & 0.598 & 0.018 & 3.850 & 0.910 \\
Liaojiawan & 8723 & 0.363 & 0.010 & 3.860 & 0.948 \\
Xiashan & 15975 & 1.132 & 0.012 & 2.340 & 0.920 \\
Pearson Correlation Coefficient & $0.882^{\star *}$ & $0.929^{\star \star}$ & 0.598 & $-0.908^{\star \star}$ \\
\hline
\end{tabular}

Note: The catchment size of the 10 stations were acquired from the literature [59]. However, the catchment area of other stations could not be found.

River, which is a tributary of Ganjiang River. Hence, the catchment area and confluence process of Jian Station are very different from other stations.

Even though the combined effect of the two meteorological factors, namely precipitation and air temperature, can determine the variation of water level, catchment size is of key important to the spatial variation of water level. As demonstrated in a paper studying water level changing in Polish lakes [55], lake of precipitation or its shortage does cause a decrease in the water level in a basin when it occurs in a reason that precipitation is not necessary. The current research found that, in winter, smaller amount of precipitation could result in intensive fluctuation of water level than that in summer in Poyang Lake.

The analysis of water-level time series over a whole basin plays an important role in understanding hydrodynamic characteristics and formulating ecological planning. However, many published research mainly focuses on the long-term behavior of a basin using he monthly average value of water level influenced by climate changing [55-57]. Realistically, effectively ecological planning needs to consider not only the temporal variation of water level during a long time scale but also the spatial pattern of water level at a basin scale. The research is of great help for people to understand how water level fluctuation vary with the elevation at a basin scale.

\section{Conclusions}

\subsection{Conclusions}

The paper considered water level data of 24 monitoring stations and precipitation data of 26 monitoring stations in daily units over the period from March 1, 2015 to February 28, 2017 in Poyang Lake basin. The temporal variation and spatial pattern of water level fluctuation were analyzed with the help of traditional statistical methods and permutation entropy. Additionally, the correlation between the fluctuation of water level and elevation is emphatically discussed. The results showed the following. 1) Variation of water level downstream of Poyang Lake during one year follows a single peak or a sinusoid, while it is random in upper reaches. That is, the range of water level in upper reaches is much less than that in downstream. 2) Fluctuation of water level in winter and spring is more irregular and more random than that in other seasons. This is because in winter and spring, precipitation directly causes rising in water level rather than generating surface runoff, while it is reversed in summer. 3) The ranges, standard deviation, coefficient of variation and fluctuation of water level decrease with rising in elevation. 4) In sub-basin scale, fluctuation of water level in upper reaches is more complicated than that in downstream, especially along one river. Mechanically, spatial terrain and confluence process, i.e., catchment areas, may be the main factors influencing fluctuation of water level over Poyang Lake basin. 


\subsection{Prospects}

To measure the temporal variation and spatial pattern of water level fluctuation, permutation entropy is calculated to quantify the fluctuation of water level and their correlation with elevation. This analysis has achieved various results, which may provide supplementary reference for us to formulate regional ecological planning to protect biodiversity. However, there are still certain limitations that need to be investigated in the future. Precisely, a spatial variation of water level fluctuation has been analyzed and mapped, and a correlation with elevation has been found. Mechanically, spatial terrain and confluence processes may be responsible for this phenomenon. But how? At the same time, many works, such as dams which have been built recent years, may affect the process to a certain extent. Complexity science and methods may provide a new way to understand the influencing factors. Thus, this should be considered in the future.

Supplementary Materials: Figure 4: Temporal variations of the water level during period from March 1, 2016 to February 28, 2017: (a) temporal variation of water level at Xingzi Station; (b) temporal variation of water level at Xiashan Station., Table 7: Traditional statistics of water level at 24 observation stations in 2016., Table 8: Correlation between elevation and classical statistical value of water level in 2016., Table 9: PE values of water level in different seasons and their correlations with elevation in 2016., Table 10: PE values water level at 24 stations and their correlations with elevation in 2016.

Conflicts of Interest: The founding sponsors had no role in the design of the study.

Acknowledgement: This research was jointly financed by the National Key R\&D Program of China (grant number 2017YFA0604704), and the National Natural Science Foundation of China (grant number 91725000). We are grateful to two anonymous reviewers who provided constructive suggestions which led to improvement of the paper.

\section{References}

[1] Campbell I.C. Integrated management of large rivers and their basins. Ecohydrology \& Hydrobiology, 2016, 16, 203-214.

[2] Sreeja K.G., Madhusoodhanan C.G., Eldho T.I. Coastal zones in integrated river basin management in the west coast of india: Delineation, boundary issues and implications. Ocean \& Coastal Management, 2016, 119, 1-13.
[3] Berthou S., Mailler S., Drobinski P., Arsouze T., Bastin S., Béranger K., Flaounas E., Lebeaupin Brossier C., Somot S., Stéfanon M. Influence of submonthly air-sea coupling on heavy precipitation events in the western mediterranean basin. Quarterly Journal of the Royal Meteorological Society, 2016, 142, 453471.

[4] Hulme A.L., Martin J.E. Synoptic-and frontal-scale influences on tropical transition events in the atlantic basin. Part i: A six-case survey. Monthly Weather Review, 2009, 137, 3605-3625.

[5] Nilsson C., Reidy C.A., Dynesius M., Revenga C. Fragmentation and flow regulation of the world's large river systems. Science, 2005, 308, 405-408.

[6] Latrubesse E.M., Arima E.Y., Dunne T., Park E., Baker V.R., d'Horta F.M., Wight C., Wittmann F., Zuanon J., Baker P.A. Damming the rivers of the amazon basin. Nature, 2017, 546, 363.

[7] Zhao G., Chang W., Yan J., Li X., Tong D., Zhao R., David S.J., Tai P. Spatial distribution and sources identification of polycyclic aromatic hydrocarbons in wolong lake, northeast china. Chinese Geographical Science, 2017, 27, 1003-1012.

[8] Salmon S.U., Hipsey M.R., Wake G.W., Ivey G.N., Oldham C.E. Quantifying lake water quality evolution: Coupled geochemistry, hydrodynamics, and aquatic ecology in an acidic pit lake. Environmental Science \& Technology, 2017, 51, 9864-9875.

[9] Yi Y., Yang Z., Zhang S. Ecological influence of dam construction and river-lake connectivity on migration fish habitat in the yangtze river basin, china. Procedia Environmental Sciences, 2010, 2, 1942-1954.

[10] Tranvik L.J., Downing J.A., Cotner J.B., Loiselle S.A., Striegl R.G., Ballatore T.J., Dillon P., Finlay K., Fortino K., Knoll L.B. Lakes and reservoirs as regulators of carbon cycling and climate. Limnology and Oceanography, 2009, 54, 2298-2314.

[11] Nyberg L., Evers M., Dahlström M., Pettersson A. Sustainability aspects of water regulation and flood risk reduction in lake vänern. Aquatic ecosystem health \& management, 2014, 17, 331340.

[12] Jung R.-T., Isshiki H. Application of tidal energy for purification in fresh water lake. International Journal of Naval Architecture and Ocean Engineering, 2015, 7, 212-225.

[13] Zhang F., Liu X., Zhang J., Wu R., Ma Q., Chen Y. Ecological vulnerability assessment based on multi-sources data and sd model in yinma river basin, china. Ecological Modelling, 2017, 349, 4150.

[14] Magesh N., Chandrasekar N., Elango L. Trace element concentrations in the groundwater of the tamiraparani river basin, south india: Insights from human health risk and multivariate statistical techniques. Chemosphere, 2017, 185, 468-479.

[15] Gautam S.K., Maharana C., Sharma D., Singh A.K., Tripathi J.K., Singh S.K. Evaluation of groundwater quality in the chotanagpur plateau region of the subarnarekha river basin, jharkhand state, india. Sustainability of Water Quality and Ecology, 2015, 6, 57-74.

[16] Godfray H.C.J., Beddington J.R., Crute I.R., Haddad L., Lawrence D., Muir J.F., Pretty J., Robinson S., Thomas S.M., Toulmin C. Food security: The challenge of feeding 9 billion people. science, 2010, 327, 812-818.

[17] Banwart S., Bernasconi S.M., Bloem J., Blum W., Brandao M., Brantley S., Chabaux F., Duffy C., Kram P., Lair G. Soil processes and functions in critical zone observatories: Hypotheses and experimental design. Vadose Zone Journal, 2011, 10, 974-987. 
[18] Awange J.L., Sharifi M.A., Ogonda G., Wickert J., Grafarend E.W., Omulo M.A. The falling lake victoria water level: Grace, trimm and champ satellite analysis of the lake basin. Water Resources Management, 2008, 22, 775-796.

[19] Wedderburn S.D., Hammer M.P., Bice C.M. Shifts in smallbodied fish assemblages resulting from drought-induced water level recession in terminating lakes of the murray-darling basin, australia. Hydrobiologia, 2012, 691, 35-46.

[20] Zhang M., Wang S., Fu B., Gao G., Shen Q. Ecological effects and potential risks of the water diversion project in the heihe river basin. Science of The Total Environment, 2018, 619, 794-803.

[21] Yi J., Zhao Y., Shao M.a., Li H., Jiang R., Hill R.L., Si B. Hydrological processes and eco-hydrological effects of farmlandforest-desert transition zone in the middle reaches of heihe river basin, gansu, china. Journal of Hydrology, 2015, 529, 16901700.

[22] Benson L.V., Thompson R.S. Lake-level variation in the lahontan basin for the past 50,000 years. Quaternary Research, 1987, 28, 69-85.

[23] Hu X., Lu L. Spatio-temporal variability of groundwater level in the middle heihe river basin. Journal of Desert Research, 2009, 29, 777-784.

[24] Yuan Y., Zeng G., Liang J., Huang L., Hua S., Li F., Zhu Y., Wu H., Liu J., He X. Variation of water level in dongting lake over a 50year period: Implications for the impacts of anthropogenic and climatic factors. Journal of Hydrology, 2015, 525, 450-456.

[25] Zohary T., Ostrovsky I. Ecological impacts of excessive water level fluctuations in stratified freshwater lakes. Inland Waters, 2011, 1, 47-59.

[26] Altunkaynak A. Predicting water level fluctuations in lake michigan-huron using wavelet-expert system methods. Water resources management, 2014, 28, 2293-2314.

[27] Liu Y., Liu C., Wang D. Understanding atmospheric behaviour in terms of entropy: A review of applications of the second law of thermodynamics to meteorology. Entropy, 2011, 13, 211-240.

[28] Liu J., Dietz T., Carpenter S.R., Alberti M., Folke C., Moran E., Pell A.N., Deadman P., Kratz T., Lubchenco J. Complexity of coupled human and natural systems. science, 2007, 317, 1513-1516.

[29] Dozier J. Mountain hydrology, snow color, and the fourth paradigm. Eos, Transactions American Geophysical Union, 2011, 92, 373-374.

[30] Ludescher J., Bunde A., Franzke C.L., Schellnhuber H.J. Longterm persistence enhances uncertainty about anthropogenic warming of antarctica. Climate dynamics, 2016, 46, 263-271.

[31] Pele D.T., Lazar E., Dufour A. Information entropy and measures of market risk. Entropy, 2017, 19, 226.

[32] Gao J., Hu J., Tung W.-W., Cao Y., Sarshar N., Roychowdhury V.P. Assessment of long-range correlation in time series: How to avoid pitfalls. Physical Review E, 2006, 73, 016117.

[33] Gao J., Sultan H., Hu J., Tung W.-W. Denoising nonlinear time series by adaptive filtering and wavelet shrinkage: A comparison. IEEE Signal Processing Letters, 2010, 17, 237-240.

[34] Kanafi M.M., Tuononen A.J. Top topography surface roughness power spectrum for pavement friction evaluation. Tribology International, 2017, 107, 240-249.

[35] Gao J., Liu F., Zhang J., Hu J., Cao Y. Information entropy as a basic building block of complexity theory. Entropy, 2013, 15, 33963418.

[36] Bandt C., Pompe B. Permutation entropy: A natural complexity measure for time series. Physical review letters, 2002, 88,
174102.

[37] Li X., Li C. Pretreatment and wavelength selection method for near-infrared spectra signal based on improved ceemdan energy entropy and permutation entropy. Entropy, 2017, 19, 380.

[38] Hou Y., Liu F., Gao J., Cheng C., Song C. Characterizing complexity changes in chinese stock markets by permutation entropy. Entropy, 2017, 19, 514.

[39] Toomey J., Kane D. Mapping the dynamic complexity of a semiconductor laser with optical feedback using permutation entropy. Optics express, 2014, 22, 1713-1725.

[40] Kalpakis K., Yang S., Hu P.F., Mackenzie C.F., Stansbury L.G., Stein D.M., Scalea T.M. Permutation entropy analysis of vital signs data for outcome prediction of patients with severe traumatic brain injury. Computers in biology and medicine, 2015, $56,167-174$.

[41] Gao J., Hu J., Tung W.-w. Entropy measures for biological signal analyses. Nonlinear Dynamics, 2012, 68, 431-444.

[42] Stosic T., Telesca L., de Souza Ferreira D.V., Stosic B. Investigating anthropically induced effects in streamflow dynamics by using permutation entropy and statistical complexity analysis: A case study. Journal of Hydrology, 2016, 540, 1136-1145.

[43] Ji Y., Xu X., Wan J., Hu S. Research on simulation of diversion flood routing for kangshang flood storage in poyang lake region. Procedia Engineering, 2012, 28, 740-743.

[44] Guo H., Hu Q., Zhang Q., Wang Y. Annual variations in climatic and hydrological processes and related flood and drought occurrences in the poyang lake basin. Acta Geographica Sinica, 2012, 67, 699-709.

[45] Wang H., Zhao Y., Liang D., Deng Y., Pang Y. 30+ year evolution of cu in the surface sediment of lake poyang, china. Chemosphere, 2017, 168, 1604-1612.

[46] Huang A., Peng W., Liu X., Du Y., Zhang S., Wang S., Du F., Dong F. Characteristics and factors influencing the hysteresis of water area-stage curves for poyang lake. Water, 2017, 9, 938.

[47] Wu G., Liu Y. Seasonal water exchanges between china's poyang lake and its saucer-shaped depressions on river deltas. Water, 2017, 9, 884.

[48] Duan W., He B., Nover D., Yang G., Chen W., Meng H., Zou S., Liu C. Water quality assessment and pollution source identification of the eastern poyang lake basin using multivariate statistical methods. Sustainability, 2016, 8, 133.

[49] Schwartz T.U., Walczak R., Blobel G. Circular permutation as a tool to reduce surface entropy triggers crystallization of the signal recognition particle receptor $\beta$ subunit. Protein science, 2004, 13, 2814-2818.

[50] Pardo-Igúzquiza E., Rodríguez-Tovar F.J. Maxenper: A program for maximum entropy spectral estimation with assessment of statistical significance by the permutation test. Computers \& Geosciences, 2005, 31, 555-567.

[51] Riedl M., Müller A., Wessel N. Practical considerations of permutation entropy. The European Physical Journal Special Topics, 2013, 222, 249-262.

[52] Roeloffs E.A. Persistent water level changes in a well near parkfield, california, due to local and distant earthquakes. Journal of Geophysical Research: Solid Earth, 1998, 103, 869-889.

[53] Wassmann R., Hien N.X., Hoanh C.T., Tuong T.P. Sea level rise affecting the vietnamese mekong delta: Water elevation in the flood season and implications for rice production. Climatic Change, 2004, 66, 89-107. 
[54] Zhang Q., Jiang T., Gemmer M., Becker S. Precipitation, temperature and runoff analysis from 1950 to 2002 in the yangtze basin, china/analyse des précipitations, températures et débits de 1950 à 2002 dans le bassin du yangtze, en chine. Hydrological Sciences Journal, 2005, 50.

[55] Wrzesiński D., Ptak M. Water level changes in polish lakes during 1976-2010. Journal of Geographical Sciences, 2016, 26, 83101.

[56] Ptak M., Wrzesiński D., Choiński A. Long-term changes in the hydrological regime of high mountain lake morskie oko (tatra mountains, central europe). Journal of Hydrology and Hydromechanics, 2017, 65, 146-153.
[57] Arkian F., Nicholson S.E., Ziaie B. Meteorological factors affecting the sudden decline in lake urmia's water level. Theoretical and Applied Climatology, 2018, 131, 641-651.

[58] Zhao G., Hörmann G., Fohrer N., Zhang Z., Zhai J. Streamflow trends and climate variability impacts in poyang lake basin, china. Water resources management, 2010, 24, 689-706.

[59] Hu S.L, Analysis of the influence of water conservancy construction on ecological environment in Poyang Lake District Study on ecological. NanChang University, 2017. (in Chinese) 